\title{
Research on Applications of Earthquake Response Spectrum in Engineering Designs
}

\author{
ChangXian Zhou ${ }^{1, a}$, ShaoPeng Zheng ${ }^{1, b}$ and CongRongRen ${ }^{1, c}$ \\ ${ }^{1}$ Xiamen city Jimei District Sheng Road No. 669Xiamen Research Center of Seismology Survey \\ a41500619@qq.com, b41500619@qq.com, c41500619@qq.com
}

\section{Keywords: Earthquake; Response Spectrum; Applications}

\begin{abstract}
Earthquake-proof buildings are earthquake disaster mitigation priority work. Earthquake building structure may be determined, according to the design response spectrum method for determining been widely used in seismic design of buildings structures. In this paper, the structure should be designed to avoid damage in the earthquake collapsed, but the study of structural collapse behavior conducive to a better understanding of the mechanism of structural collapse and find effective anti-collapse methods. This paper was developed to simulate the complex structure collapsed procedures, through the numerical results were compared with the test, indicating that the numerical model can simulate the structural members of a variety of extreme nonlinear behavior. The structure is replaced by an equivalent single degree of freedom system corresponding to each mode and each equivalent displacement is determined using the proposed method. Thus, the seismic safety evaluation plays an important role. In recent years, with the accumulation of mature safety evaluation theory and engineering experience, the safety assessment has made great progress.
\end{abstract}

\section{Theoretical Introduction of Earthquake Response Spectrum}

Earthquake response spectrum can be widely applied in a single degree of freedom system, and can be decomposed into a modal method is applied to multi-degree of freedom system in seismic response. Due to post-structuralism into elastic-plastic response phase, the superposition principle no longer applies, and therefore, for most multi-degree of freedom system, application inelastic response spectra of seismic response analysis can only approximate displacement and performance evaluation structure, can't be considered high modes of influence.

Research on the structure at this stage whether it is anti-progressive collapse of the entire structure from the global focus of the system, or from the details of the start node structure, and even research has a lot of progress from the failure mechanism inside, but we can find a lot of scholars using planar framework for analysis, not a plane frame, there are many linear static analysis, nonlinear dynamic analysis in recent years increasingly popular. As the height increases, lateral structure under lateral loads increases rapidly. Tall buildings vertical loads is accumulated in the vertical component from top to bottom layer by layer transfer, which will produce large axial deformation ${ }^{[1]}$.

Therefore, the application of inelastic response spectra in engineering design is inelastic response spectra become standard design spectrum difficulties. Over half a century, many scholars have nonlinear seismic response of structures have done a lot of research, and made many useful insights. However, the current inelastic response spectra for research also can provide a major seismic design of this concept, and the relationship between the structure and the earthquake ground motion characteristics and structural dynamic parameters understanding. Tall building in central axial edge components and component deformation difference between the larger, and thus will cause a large additional moment. Tall Buildings in earthquake zones should ensure sufficient ductility to absorb and dissipate seismic energy. Therefore, in order to ensure that the structure of the plastic deformation still has good seismic performance after entering, seismic structure to take appropriate measures to ensure the structure has good ductility. 


\section{Seismic Performance Targets of Engineering Designs}

Seismic design performance goals of buildings refer a set expected performance level of the building to earthquake ground motion. Performance level of the building includes structural, non-structural and performance of various combinations of standard construction of ancillary facilities. The current tall buildings refer the height or exceed specifications in terms of rules, procedures scope of tall buildings projects. Tall buildings structural performance targets under different levels of different earthquakes, seismic performance can be divided into the following standards ${ }^{[2]}$ :

The structure has good condition and no damage after the earthquake, generally without repair we can continue to use, and people will not be due to structural damage caused by injury. Structure largely has good condition after the earthquake, only a few minor cracks in components, we generally do not need a little repair or continue to use, people will not be due to structural damage caused by injury. After the earthquake, weak parts of the structure and components of the important parts are in good condition with no damage, some other parts of the selected member has some ductility obvious cracks can be repaired and continued safe use.

After the earthquake weak parts of the structure and components of the important parts have minor damage and minor cracks, some other parts of the selected member has moderate damage occurred ductility, obvious cracks into yielding stage, we need to take some safety repairs and measures in order to continue to use. Moderate structure damage occurs in the earthquake, the majority of members have minor damage, some elements have moderate damage, yielding a significant crack, we need to take security measures that people can't secure access .After repairs and proper reinforcement, we can continue to use. The structures appears significant damage in the earthquake, the majority of members have moderate damage, yielding a significant crack, some members severely are damaged, but the whole structure does not collapse, partial collapse does not occur, officers will be hurt without life-threatening.

It is emphasized that the irregular structures of the ductility degree directly affect the level of deformation. This means that the seismic design tall building structure should be combined with the degree of structural irregularities, improved the structural capacity, improved ductility deformation or both of these two methods to improve the selection of reasonable and realistic processing means to ensure safety performance. In order to design the seismic performance of the proposed method overrun rise building structure design, the owners need to measure the costs required for the design, seismic examined experts determine the feasibility of a special gauge designed around the needs of structural safety and architectural design coordination ${ }^{[3]}$.

\section{Application of Earthquake Response Spectrum}

With the performance of the proposed design theory, based on the performance of seismic design, the system response is equivalent to elastic-plastic systems were analyzed, and (improve) the ability spectroscopy analysis is a method, making inelastic response spectra calculations structure bomb plastic displacement of one side to the initial application. However, due to the limitations of their own, generally limited to the first mode in response to the main structure, a greater impact for the higher modes of structural response, will bring greater error; therefore, this scholar has proposed a modal method. In short, the performance of a law designed to reduce the response spectra for elastic-plastic applications provide a way out, but to make the inelastic response spectra extended to the seismic design specification there are still many difficulties ${ }^{[4]}$.

Progressive collapse is defined as the collapse of the whole building due to local weak stories or weak zones. In this paper, collapse should theoretically be avoided for any building under any earthquake, it is necessary to study the collapse behavior of buildings to acquire a better understanding of the collapse mechanism and to find efficient methods to prevent it. The collapse process highly depends on the feature of the whole structural system, so numerical simulation becomes a major method to study it. Because for the high-level framework - core tube structure collapsed mainly because of damage caused compression and shear walls, steel buckling instability 
strain and therefore the impact of natural influence is bigger than steel strain to pull off.

For complex structures in terms of their weaknesses may not be only one. Due to the randomness of the earthquake, the same for the structure, seismic analysis of seismic waves used in the plant structure is fit five damping ratio $(200,300,400,500,700)$. The time course of a single and single set of ground motion acceleration peaks during the calculation of the calibration Q $3 \mathrm{~h}$. Based on this, the paper has chosen to fit five damping ratio (200,300,400,500,700) standard design response spectrum of artificial-term foundation inversion AP1000 design calculations, different damping time curve than the corresponding response spectra and AP1000 CSDRS fit curve shown, time curve of the power spectral density and density requirements of the relationship between power spectrum shown in seismic waves meet regulatory requirements. Fig. 1 shows the sleeted seismic waves.
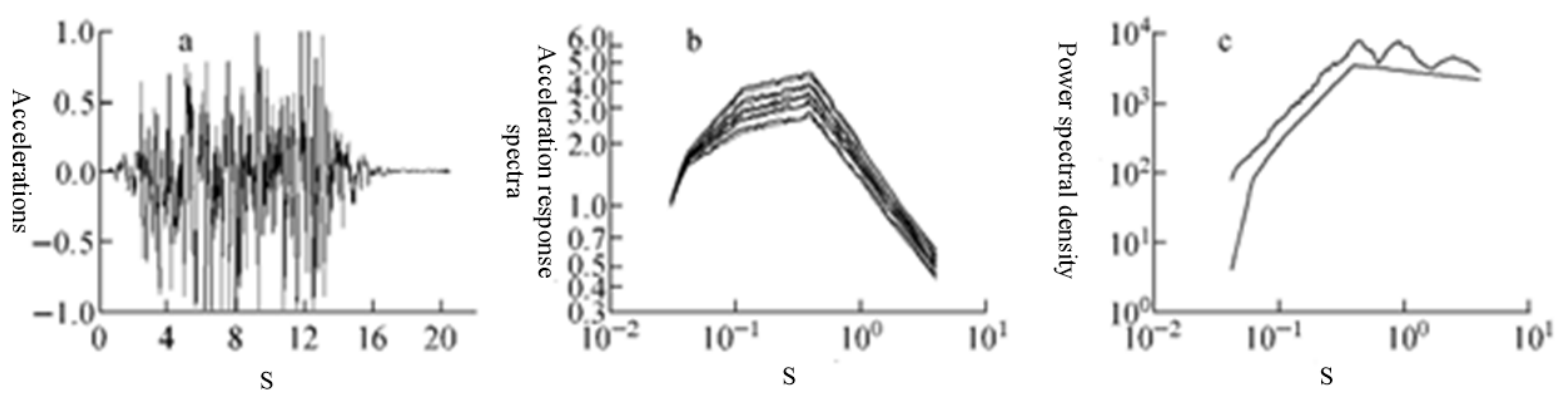

Fig. 1.The sleeted seismic waves

\section{Improve Shock Resistance of the Structure}

Structural damage occurred mostly because of the continuity of the role of collapse accident loads, and the accident is difficult to estimate the load, so this is designed to bring great difficulty, it is difficult to give a clear specification guidelines. Therefore, the structure of today's designers should consider a more comprehensive knowledge and understanding of key components, the nodes connecting structure, redundancy, etc., in order to cope with the design requirements ${ }^{[5]}$.

It is difficult to predict the occurrence of an accident, for the terrorist attacks may also be preventive, but for earthquakes and other natural disasters, the powerless, the same building measures only the outer edge of the measures to prevent the occurrence of progressive collapse, in order to radically reduce accident disasters is necessary from the enhanced ductility, increased redundancy as other point of view, the internal structure of the reinforcing structure, so as to achieve the purpose of preventing of progressive collapse structure. Fig. 2 shows the measures to prevent the progressive collapse of the structure.

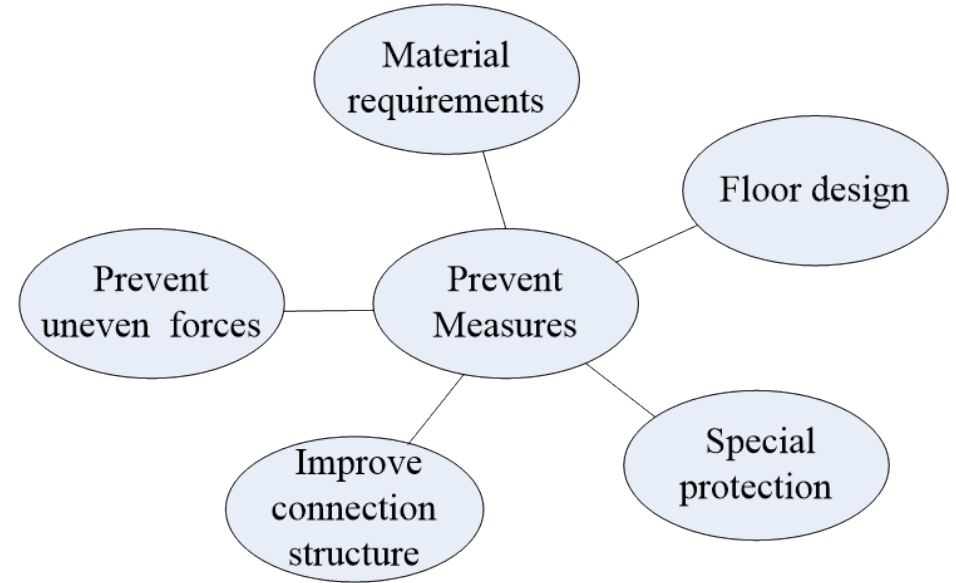

Fig. 2.The measures to prevent the progressive collapse of the structure

In order to minimize staff time to escape to fight, we need to ensure that the structure will not collapse immediately at the time of the attack was accidental loads, which need to be strengthened ductile structures. To ensure the structural ductility factor is vertical "light, good" choice of 
materials, light weight material that is good compared with ductile materials. We should design increases the size and strength of the cross-section of the material, because the only way to ensure lateral stiffness mutation does not occur uniformly continuous variation of lateral stiffness of the structure can't be prevented because of local weakness leaving structural collapse. When a column due to the action of accidental loss of load bearing capacity, requiring configured through the reinforcement of the adjacent beam has sufficient tensile strength to achieve its load across two bays will be adjacent to the target column.

The role of key components for the entire structure should not be overlooked. It is almost intact determine whether or not the structure will generate continuity of collapse. Strengthen key component to ensure that accidental loads when struck, to have sufficient strength and ductility and not to fail immediately. The role of accidental load floor make the force changes direction, increasing the floor span direction reinforcement force, two-way reinforcement, we can make a root structure, even failure in floor beams span direction, can still span direction through floor and changing the direction of the force to continue to bear the load, thereby preventing the collapse of the floor.

\section{Conclusions}

With the development of our country economy, more and more super tall buildings are being built. While its beauties attract the attention of the people and they provide sufficient and comfort space to our people, it is very important to evaluate and its safety during severe earthquake. The particle element method has the computation accuracy of finite element method during the continuum phase and the computation capability of discrete element method during the non-continuum phase, could be used for strong nonlinear dynamics simulation of building structure collapse. Seismic safety evaluation related to the sustainable development of people's lives and property safety and economy. Major construction projects and may induce serious secondary disasters construction, seismic safety evaluation must be carried out, and based on the results of seismic safety evaluation to determine the requirements for seismic resistance, seismic fortification.

\section{References}

[1] Lynn K M, Isobe D. Structural collapse analysis of framed structures under impact loads using ASI-Gauss finite element method [J] International Journal of Impact Engineer, 2007, 34(9): 1500-1516.

[2] Lu Xinzheng, Ye Lieping, Miao Zhiwei. Elasto-plastic analysis of buildings against earthquake [M], 2009.

[3] van de Lindt J W, Pei S L, Pryor S E, et al. Experimental seismic response of a full-scale six-story light-frame wood building. J Struct Eng-ASCE, 2010, 136: 1262-1272.

[4] Li Y, Lu X Z, Guan H, et al. An improved tie force method for progressive collapse resistance design of reinforced concrete frame structures. Eng Struct, 2011, 33: 2931-2942.

[5] Sasani M, Kazemi A, Sagiroglu S, et al. Progressive Collapse Resistance of an Actual11-Story Structure Subjected to Severe Initial Damage [J]. Journal of Structural Engineering. 2011, 137(9): 893-902. 